\title{
POLLEN MORPHOLOGY OF PINUS ULIGINOSA NEUM. AND PINUS UNCINATA RAMOND EX DC IN AN EXPERIMENTAL CULTURE
}

\author{
Maegorzata Klimko, Joanna ByKowska
}

\author{
M. Klimko, Department of Botany, Poznań University of Life Sciences, Wojska Polskiego 71 C, 60-625 \\ Poznań, Poland, e-mail: klim@up.poznan.pl \\ J. Bykowska, Department of Dendrology and Nursery, Poznań University of Life Sciences, Baranowo, \\ Szamotulska 28, 62-081 Przeźmierowo, Poland, e-mail: jozal@up.poznan.pl
}

(Received: March 10, 2015. Accepted: June 20, 2015)

\begin{abstract}
Aвstract. Pollen grains of Pinus uliginosa and P. uncinata were examined by light and scanning electron microscopy. The pollen grains were bisaccate and monosulcate. The corpus-saccus attachment was distinct. The pollen corpus exine sculpture was verrucate-rugulate and deeply sculptured. The surface of the tectum was with or without small grana and it was perforate. The saccus sexine ornamentation was reticulate and irregularly perforate. The tectum surface characters in the proximal and distal view of the corpus and saccus were less variable and they did not provide good criteria to identify the species under study. Among the $P$. uncinata from the Forest Arboretum there were differences observed in the size, shape and height of elevation and sculpture on the corpus between pollen grains of the same specimen. This study of the pollen grain morphology of the corpus and saccus provided some important new data.
\end{abstract}

KeY Words: Pinus uliginosa, Pinus uncinata, pollen morphology, LM, SEM

\section{INTRODUCTION}

Pinus uliginosa and Pinus uncinata are two of more than a dozen pine species that can naturally be found in Europe (StaszKiewicz 1966, Seneta 1987). Their taxonomic position is complicated and it has not been fully determined. Over the years they were treated as separate species or they were included into the Pinus mugo complex due to suggestions pointing to their hybrid origin. STASZKIEWICZ \& TYSZKIEWICZ (1972) found Pinus uncinata and Pinus mugo to be strongly related species, whereas SzWEYKOWSKI (1969) called the population of Pinus uliginosa from the Great Peat Bog of Batorów a relic of a hybrid swarm of Pinus mugo and Pinus sylvestris. On the other hand, KrzaKowa et al. (1984) hypothesised that $P$. uliginosa might be an isolated, marginal population of $P$. uncinata.

The literature provides numerous elaborations which investigate and/or determine the range of variability of $P$. uliginosa and $P$. uncinata. Studies on the morphology and anatomy of $P$. uliginosa and $P$. sylvestris needles were conducted by BORATYŃSKA \& LEWANDOWSKA (2009) and BorATYŃsKA et al. (2011), whereas SobierajSKA \& BoratYŃsKa (2008) studied $P$. mugo needles. Studies on the P. uliginosa cone morphology were conducted by MARCYSIAK et al. (2003), whereas MARCYSIAK (2004) studied P. uncinata cones. According to BoRATYŃSKA et al. (2011), the combination of needle and cone morphological traits is a good tool for distinguishing between $P$. sylvestris, $P$. uncinata, P. mugo and P. uliginosa with very high probability.

The palynological literature provides little data concerning the size and exine sculpture on the corpus and saccus of pollen grains in the taxa under study. KLaus (1978) described the tectum of the corpus and saccus of $P$. uncinata collected in the Pyrenees on the eastern French side near Col de Llose (1740 m). NAKAGAWA et al. (2000) presented the size (the corpus breadth and basal width of the saccus) and the surface structure of the corpus pollen grains $P$. uncinata from the southern French Alps. No information on the micromorphology of $P$. uliginosa pollen has been found.

The main aims of this study were to: 1 . describe variation in the pollen grain morphology of $P$. uliginosa and $P$. uncinata; 2 . describe and document the pollen grain micromorphology; 3 . supply new data which can be used for identification of the species under study. 
Table 1. Mean values ( \pm SE) and ranges (minimum-maximum) of the morphological traits of Pinus uliginosa and P. uncinata pollen grain and saccus

\begin{tabular}{|c|c|c|c|c|}
\hline Character & P. uliginosa (DG) & P. uncinata (DG) & P. uncinata (FA) & ANOVA \\
\hline \multicolumn{5}{|c|}{ Pollen grain } \\
\hline Width of the pollen grain $(\mu \mathrm{m})$ & $\begin{array}{l}69.02 \pm 2.5 \mathrm{~b} \\
62.92-80.08\end{array}$ & $\begin{array}{l}65.11 \pm 2.8 \mathrm{a} \\
60.06-68.64\end{array}$ & $\begin{array}{l}73.50 \pm 3.4 c \\
65.78-80.08\end{array}$ & $\begin{array}{c}F=63.09 \\
P<0.01\end{array}$ \\
\hline Width of the corpus $(\mu \mathrm{m})$ & $\begin{array}{l}47.78 \pm 4.8 \mathrm{a} \\
33.84-55.29\end{array}$ & $\begin{array}{l}50.79 \pm 4.9 b \\
36.28-58.95\end{array}$ & $\begin{array}{l}58.81 \pm 3.7 c \\
50.57-65.63\end{array}$ & $\begin{array}{c}F=48.03 \\
P<0.01\end{array}$ \\
\hline Depth of the corpus $(\mu \mathrm{m})$ & $\begin{array}{l}46.05 \pm 2.3 \mathrm{a} \\
40.04-48.62\end{array}$ & $\begin{array}{l}45.86 \pm 2.3 \mathrm{a} \\
42.90-51.48\end{array}$ & $\begin{array}{l}49.19 \pm 3.1 \mathrm{~b} \\
40.04-54.34\end{array}$ & $\begin{array}{c}F=15.46 \\
P<0.01\end{array}$ \\
\hline Shape of the corpus (width/depth ratio) & $\begin{array}{c}1.05 \pm 0.13 \mathrm{a} \\
0.74-1.28\end{array}$ & $\begin{array}{c}1.10 \pm 0.14 b \\
0.85-1.37\end{array}$ & $\begin{array}{c}1.19 \pm 0.09 \mathrm{c} \\
0.99-1.35\end{array}$ & $\begin{array}{c}F=15.18 \\
P<0.01\end{array}$ \\
\hline Distance between the sacci $(\mu \mathrm{m})$ & $\begin{array}{l}17.64 \pm 2.0 \mathrm{~b} \\
14.30-20.02\end{array}$ & $\begin{array}{l}15.73 \pm 2.1 \mathrm{a} \\
11.44-20.02\end{array}$ & $\begin{array}{l}15.63 \pm 1.8 \mathrm{a} \\
14.30-20.02\end{array}$ & $\begin{array}{l}F=9.89 \\
P<0.01\end{array}$ \\
\hline \multicolumn{5}{|c|}{ Left saccus } \\
\hline Width $(\mu \mathrm{m})$ & $\begin{array}{l}36.04 \pm 2.8 \mathrm{~b} \\
31.46-42.90\end{array}$ & $\begin{array}{l}34.42 \pm 2.3 \mathrm{a} \\
31.46-37.18\end{array}$ & $\begin{array}{l}39.66 \pm 2.5 c \\
34.32-45.76\end{array}$ & $\begin{array}{c}F=34.00 \\
P<0.01\end{array}$ \\
\hline Depth $(\mu \mathrm{m})$ & $\begin{array}{l}25.55 \pm 2.4 \mathrm{a} \\
22.88-31.46\end{array}$ & $\begin{array}{l}24.79 \pm 1.9 \mathrm{a} \\
22.88-28.60\end{array}$ & $\begin{array}{l}28.70 \pm 1.6 \mathrm{~b} \\
25.74-31.46\end{array}$ & $\begin{array}{c}F=33.01 \\
P<0.01\end{array}$ \\
\hline Shape (width/depth ratio) & $\begin{array}{c}1.42 \pm 0.12 \mathrm{a} \\
1.10-1.63\end{array}$ & $\begin{array}{c}1.39 \pm 0.10 \mathrm{a} \\
1.20-1.50\end{array}$ & $\begin{array}{c}1.38 \pm 0.08 \mathrm{a} \\
1.27-1.60\end{array}$ & $\begin{array}{l}F=0.84 \\
P=0.44\end{array}$ \\
\hline \multicolumn{5}{|c|}{ Right saccus } \\
\hline Width $(\mu \mathrm{m})$ & $\begin{array}{l}36.80 \pm 2.3 \mathrm{~b} \\
31.46-42.90\end{array}$ & $\begin{array}{l}34.99 \pm 2.1 \mathrm{a} \\
31.46-40.04\end{array}$ & $\begin{array}{l}39.85 \pm 2.9 c \\
37.18-45.76\end{array}$ & $\begin{array}{c}F=29.78 \\
P<0.01\end{array}$ \\
\hline Depth $(\mu \mathrm{m})$ & $\begin{array}{l}25.83 \pm 1.4 b \\
22.88-28.60\end{array}$ & $\begin{array}{l}24.60 \pm 1.4 \mathrm{a} \\
22.88-25.74\end{array}$ & $\begin{array}{l}29.17 \pm 2.0 c \\
25.74-34.32\end{array}$ & $\begin{array}{c}F=61.70 \\
P<0.01\end{array}$ \\
\hline Shape (width/depth ratio) & $\begin{array}{c}1.43 \pm 0.10 \mathrm{a} \\
1.22-1.63\end{array}$ & $\begin{array}{c}1.42 \pm 0.10 \mathrm{a} \\
1.33-1.75\end{array}$ & $\begin{array}{c}1.37 \pm 0.09 \mathrm{a} \\
1.18-1.56\end{array}$ & $\begin{array}{l}F=3.48 \\
P=0.04\end{array}$ \\
\hline
\end{tabular}

One way ANOVAs were performed separately for each features to determine the differences among taxa studied. Same letters indicate a lack of statistically significant differences between analysed taxa according to Tukey's a posteriori test $(\mathrm{P}<0.05)$.

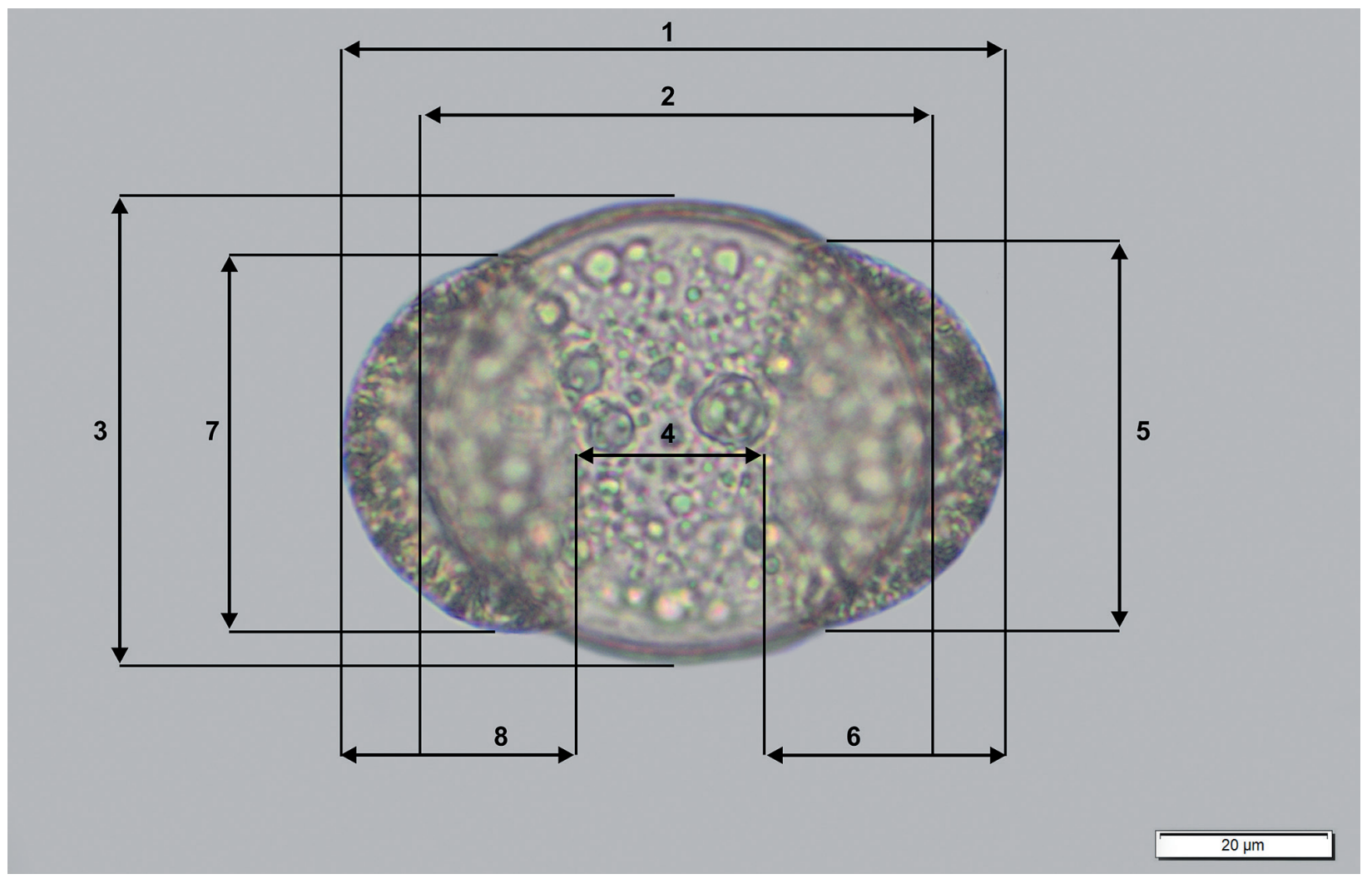

Fig. 1. Pollen grain dimension measurement method: 1 - pollen grain width, 2 - corpus width, 3 - corpus depth, 4 - distance between sacci, 5 - right saccus width, 6 - right saccus depth, 7 - left saccus width, 8 - left saccus depth (after ERDTMAN 1957, modified) 


\section{MATERIAL AND METHODS}

Pollen grains were collected from three pine specimens growing in an experimental plot in the Dendrological Garden, Poznań University of Life Sciences (DG) and the Forest Arboretum in Zielonka (FA), Poland. Two pines came from seeds collected from natural habitats. Pinus uliginosa (no. 0526) growing in the Dendrological Garden comes from the Nature Reserve Peat-Bog near Węgliniec, and P. uncinata growing in the Forest Arboretum was obtained from seeds collected in the Pyrenees. The origin of the third tree under analysis, i.e. P. uncinata, no. 0790 , is unknown.

Each sample was represented by 30 pollen grains. Table 1 lists the traits measured (in the polar view), and Figure 1 shows the measurement method. The pollen terminology was adopted from ERDTMAN (1957), Kremp (1965), Bagnell (1975) and FÆGRI \& IVERSEN (1975).

The pollen grains were examined with a light microscope Olympus BX SC30 (LM) and with a scanning electron microscope (SEM) to obtain comprehensive information about the general morphology, cappae exine sculpture and saccus sexine sculpture. The SEM investigation was conducted on the pollen grains which were dried in the air, whereas the LM pollen was treated with $10 \% \mathrm{KOH}$ (FrederIKSEN 1978). The SEM micrographs were taken with a Zeiss EVO 40 microscope at the Electron Microscopy Laboratory, Faculty of Biology, Adam Mickiewicz University, Poznań, Poland. Prior to the observation, the prepared material was sputtered with gold by means of an SCB 050 ion sputter. The study was documented with photographs taken during the observation, mostly magnified $\times 5000$ for the shape and $\times 20000$ for the exine sculpture. The micromorphological traits of the pollen grains were observed in the proximal view of the corpus and saccus.

The biometric data were analysed statistically with STATISTICA 10 (StatSoft, Inc. 2011). For each pollen trait, univariate analysis of variance (ANOVA) was used to examine mean differences between the species under study. When there were significant differences observed, the ANOVAs were followed by Tukey's HSD test at $\alpha=0.05$.

\section{RESULTS}

\section{PINUS ULIGINOSA (TABLE 1, FIG. 2)}

The width of the pollen grains measured with both sacci ranged from 62.92 to $80.08 \mu \mathrm{m}$. On average the corpus was about $48 \mu \mathrm{m}$ wide and about 46 $\mu \mathrm{m}$ deep. Its shape was prolate-spheroidal (Fig. 2A) (the average width/depth of corpus ratio was 1.05). Both prolate-shaped sacci were similar in size (Fig.
$2 \mathrm{E})$. The distance between them was very large, on average $17.64 \mu \mathrm{m}$.

The proximal exine surface of the cappae was verrucate-rugulate, perforate (Fig. 2B, D). There were very sparse micrograna irregularly distributed over the surface of the cappae. The elevations on the cappae were irregular in size and height, and the pattern was evident on the majority of pollen grains. The caps separated from each other and a few chambers fused (Fig. 2B). The surface of the sacci was reticulate (Fig. 2E, F), slightly undulate in the region of the saccus attachment (Fig. 2A, C). The sexine sculpture of the sacci was perforate, small puncta and holes were found (Fig. 2F).

\section{PINUS UNCINATA (TABLE 1, FIGS 3, 4)}

We analysed the size of the $P$. uncinata pollen grains from two locations. There were surprising differences in the measurement results. The pollen grains collected in the Forest Arboretum in Zielonka were the biggest of all the pines under study - in terms of the total width (73.5 $\mu \mathrm{m}$ on average), the size of the corpus $(58.81 \times 49.19 \mu \mathrm{m}$ on average) and the size of the sacci (about $40 \times 29 \mu \mathrm{m}$ on average). The pollen grains collected in the Dendrological Garden were significantly different. They were over $10 \%$ smaller: their average total width was $65.11 \mu \mathrm{m}$ and the corpus was $50.79 \times 45.86 \mu \mathrm{m}$ in size. Apart from that, the corpus of the pollen grains of both $P$. uncinata specimens differed in shape. It was subprolate in the pine from the Forest Arboretum (the mean width/depth of corpus ratio is 1.19), whereas in the pine from the Dendrological Garden the shape was prolate-spheroidal (with the width/depth of corpus ratio of 1.10). The only trait where the measured values were similar was the distance between the sacci. On average it was 15.73 $\mu \mathrm{m}$ in $P$. uncinata DG and $15.63 \mu \mathrm{m}$ in P. uncinata FA. However, it was much smaller than in P. uliginosa.

The proximal exine surface of the cappae was verrucate-rugulate, perforate, with (Fig. 3B, D) or without small granules (Fig. 4B, D). The pollen grains from the specimen in the Dendrological Garden had an exine elevation with most grana clearly visible but irregularly distributed over the surface of the cappae (Fig. 3B, D). In the pollen grains from the specimen from Zielonka (FA) there were differences observed in the size, shape and height of the elevation on the corpus and the number of puncta (Fig. 4B, D). The exine elevation (Fig. 4B) was similar to the exine from the specimen in the Dendrological Garden (Fig. 3B, D) but in some pollen grains the elevation was bigger and smooth (Fig. 4D). The height of the neighbouring caps was almost identical. The ornamentation of the sacci was similar, reticulate, irregularly perforate, and there were small puncta and small holes observed. There were more perforations than on the cappae (Figs 3F, 4F). 


\section{DISCUSSION}

The available literature lacks detailed information on the morphology and micromorphology of Pinus uliginosa and P. uncinata pollen grains (Table 2 and 3 ).

As far as P. uliginosa is concerned, only CHRISTENSEN (1987) reported that the width of pollen grains of this species (with both sacci) ranged from 68.0 to $86.7 \mu \mathrm{m}$, the mean value being $74.1 \mu \mathrm{m}$. Our findings
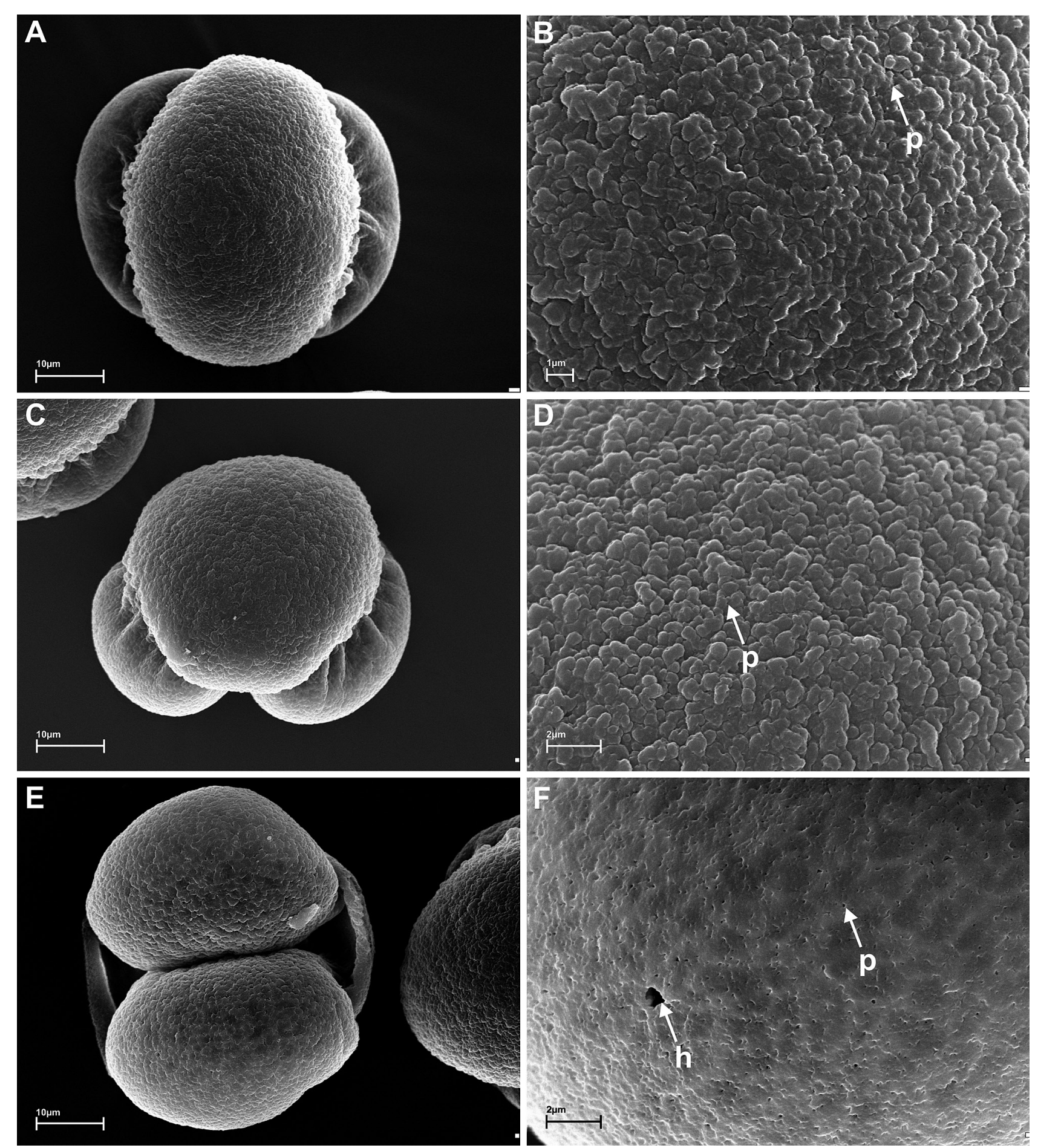

Fig. 2. Scanning electron micrographs (SEM) of pollen grains of Pinus uliginosa (DG): A - polar view, B - proximal polar area of corpus with exine ornamentation, $\mathrm{C}$ - equatorial view, D - proximal equatorial area of corpus with exine ornamentation, E - distal view, F - ornamentation of sacci ( $\mathrm{h}$ - holes, $\mathrm{p}$ - puncta) were different, but it may have been so because the measurements were taken in a different view of the pollen grains (Table 2).

The comparison of the size of $P$. uliginosa pollen grains obtained in our research with the results obtained by BүкошSкA \& KLiмко (2015) for $P$. $\times$ rhaetica, which $P$. uliginosa is often identified with, and with its potential parental species, i.e. P. mugo and P. sylvestris, revealed that the average total width of the pollen

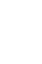


grains in $P$. uliginosa was similar to the average value in the $P$. mugo from the Forest Arboretum and $P . \times$ rhaetica no. 1 FA and 6 FA. The width of the corpus in $P$. uliginosa was similar to that in $P$. mugo DG, $P$. sylvestris and $P . \times$ rhaetica no. 2, 4, 5 and 15 from the Forest Arboretum, whereas the shape of its corpus was similar to that of $P$. $\times$ rhaetica no. 2 FA and 5 FA. The same distance between the sacci as in P. uligino- sa $(17.64 \mu \mathrm{m}$ on average) was noted in $P . \times$ rhaetica No. 14 FA. Similar sizes were observed in $P$. sylvestris $(17.73 \mu \mathrm{m})$, P. mugo FA $(18.02 \mu \mathrm{m}), P . \times$ rhaetica no. $4(17.06 \mu \mathrm{m})$ and no. 5 FA $(17.35 \mu \mathrm{m})$.

Christensen (1987) and BusinskÝ (1999) observed that $P$. uliginosa was morphologically intermediate between $P$. uncinata and $P$. mugo. This study and the study by BүкоwsKa \& KLIMKO (2015) showed that
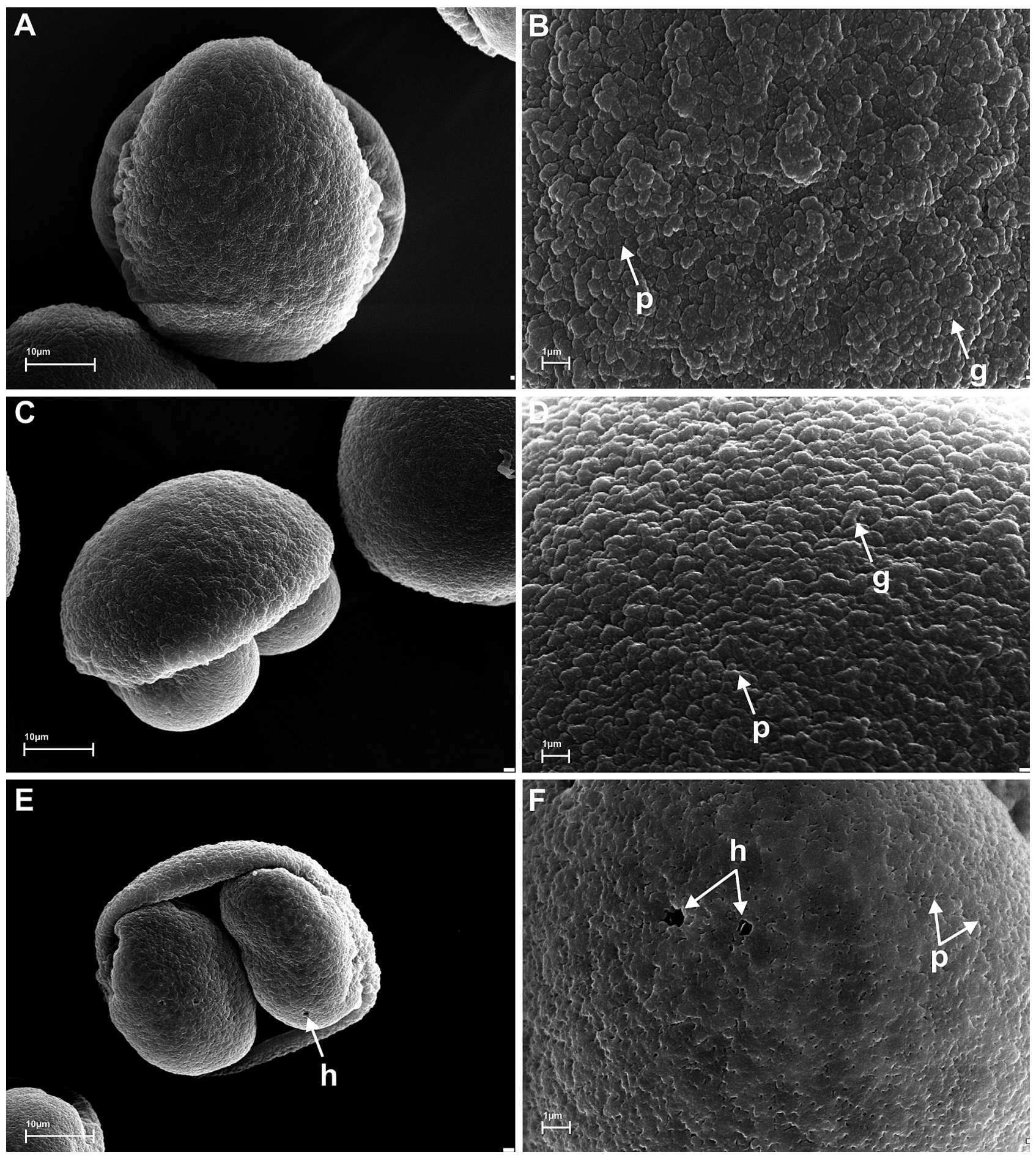

Fig. 3. Scanning electron micrographs (SEM) of pollen grains of Pinus uncinata (DG): A - polar view, B - proximal polar area of corpus with exine ornamentation, $\mathrm{C}$ - equatorial view, D - proximal equatorial area of corpus with exine ornamentation, $\mathrm{E}$ - distal view $\mathrm{F}$ - ornamentation of sacci ( $\mathrm{g}$ - grana, $\mathrm{h}$ - holes, $\mathrm{p}$ - puncta) 

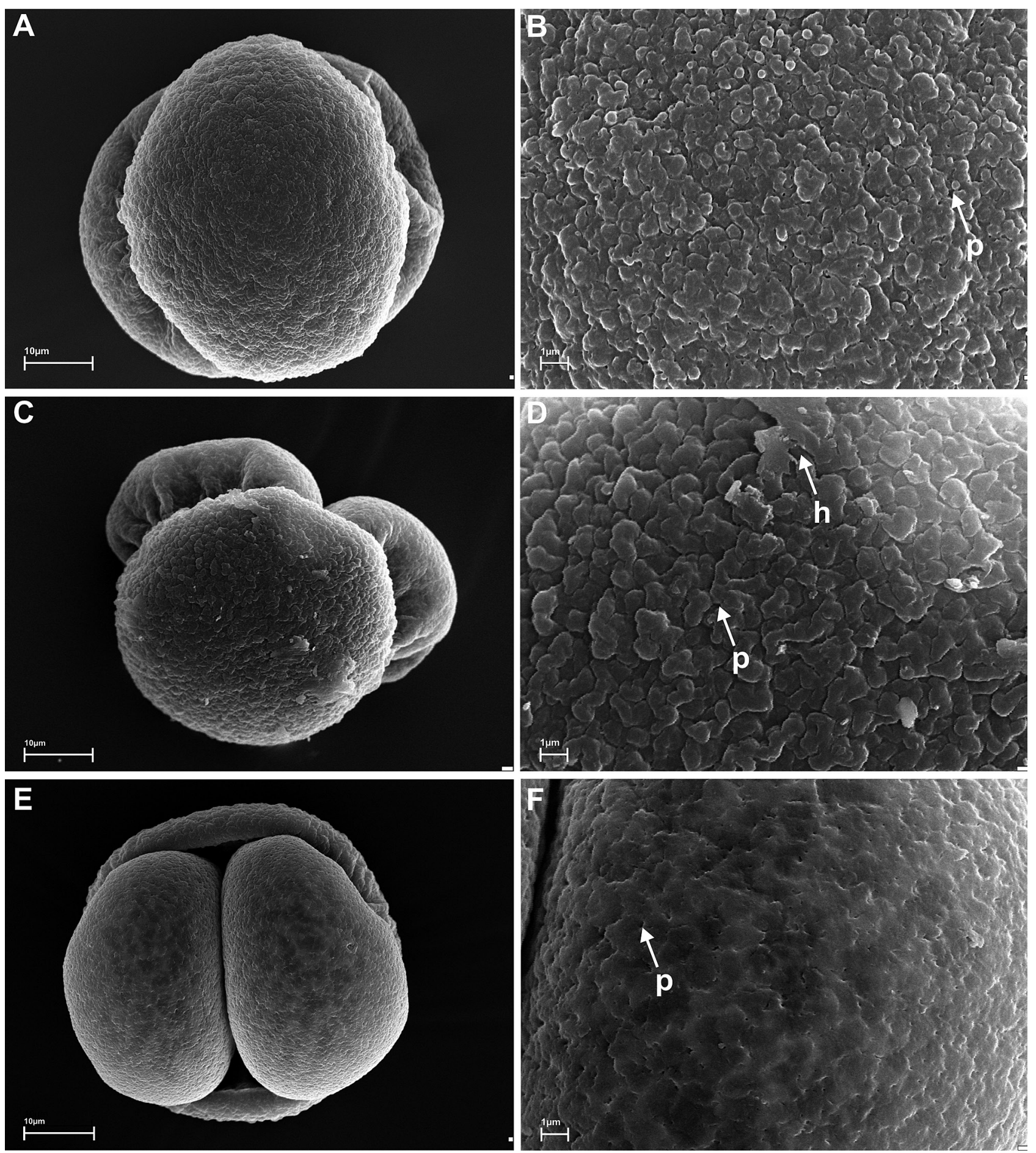

Fig. 4. Scanning electron micrographs (SEM) of pollen grains of Pinus uncinata (FA): A - polar view, B - proximal polar area of corpus with exine ornamentation, $\mathrm{C}$ - equatorial view, D - proximal equatorial area of corpus with exine ornamentation, $\mathrm{E}$ - distal view, $\mathrm{F}$ - ornamentation of sacci ( $\mathrm{h}$ - holes, $\mathrm{p}$ - puncta)

only the size of the corpus $(47.78 \times 46.05 \mu \mathrm{m})$ of $P$. uliginosa was in the intermediate position. In $P$. uncinata the average size of the corpus was $54.80 \times 47.52$ $\mu \mathrm{m}$, whereas in P. mugo it was $49.35 \times 44.14 \mu \mathrm{m}$. There were relatively big differences in the distance between the sacci. The distance in P. uliginosa was $17.64 \mu \mathrm{m}$, whereas the average distance in P. uncinata was $15.68 \mu \mathrm{m}$, and in P. mugo it was $16.87 \mu \mathrm{m}$.
In contrast to $P$. uliginosa, the available literature provided more information on the $P$. uncinata pollen morphology. CHRISTENSEN (1987) reported that the width of the $P$. uncinata pollen grains (with both sacci) ranged from 71.4 to $85.0 \mu \mathrm{m}$ (mean $78.9 \mu \mathrm{m}$ ). In our study the pollen grains of both specimens were smaller. According to NAKAGAWA et al. (2000), in the equatorial view the corpus breadth of the acetolysed 
Table 2. A comparison of individual trait values of Pinus uliginosa reported by the authors cited and the values found in our study

\begin{tabular}{|c|c|c|c|}
\hline & & Christensen (1987) & Our study \\
\hline Polle & n grain view & - & polar \\
\hline Polle & n grain acetolysis & - & non-acetolysed \\
\hline Type & of microscope & - & $\begin{array}{l}\text { LM }^{*} \\
\text { SEM }\end{array}$ \\
\hline & Pollen grain width $(\mu \mathrm{m})$ & 68.00-86.70; mean 74.10 & 62.92-80.08; mean $69.02^{*}$ \\
\hline & Corpus width $(\mu \mathrm{m})$ & - & 33.84-55.29; mean $47.78^{*}$ \\
\hline & Corpus depth $(\mu \mathrm{m})$ & - & 40.04-48.62; mean $46.05^{*}$ \\
\hline 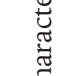 & $\begin{array}{l}\text { Corpus shape (width/depth } \\
\text { ratio) }\end{array}$ & - & $0.74-1.28$; mean $1.05^{*}$ \\
\hline $\bar{U}$ & Cappa exine sculpture & - & $\begin{array}{l}\text { verrucate-rugulate; rarely granulate; slightly perforate on the } \\
\text { proximal surface }\end{array}$ \\
\hline & Saccus sexine sculpture & - & $\begin{array}{l}\text { reticulate; slightly undulate; tectum perforate, punctate, with } \\
\text { small holes }\end{array}$ \\
\hline
\end{tabular}

pollen grains was 37-(41)-44 $\mu \mathrm{m}$. In our study the value of this trait in the polar view was greater in both of the specimens under analysis. NAKAGAWA et al. (2000) reported that the exine sculpture of the corpus was the same as in our study. In the study by Klaus (1978) conducted on P. uncinata from the Pyrenees there were differences between the pollen grains in the saccus sculpture. Our research showed that the ornamentation of the cappa in the P. uncinata pollen grains from the Dendrological Garden was the same as in the study by KLAus (1978), but the sculpture of the corpus of the pollen grains from the Pyrenees grown in the Forest Arboretum in Zielonka was different.
Some authors include $P$. uncinata into the $P$. mugo complex and/or regard it as a hybrid species. In order to check it we compared the results of our research with the results of analyses by ВүкоwsкA \& KuIMKo (2015). As far as the morphological traits are concerned, we noted that the $P$. uncinata (DG) pollen grains were similar to the P. mugo (DG) grains analysed by BYкоwsKa \& KLIMKO (2015). The total width of the P. uncinata (DG) pollen grains was slightly smaller, but the corpus was bigger. In both specimens the distance between the sacci was identical, and the shape and size of the sacci was similar.

There was a considerable similarity between Pinus $\times$ rhaetica no. 16 FA analysed by BYкоwSKA \& KLIMKO

Table 3. A comparison of individual trait values of Pinus uncinata reported by the authors cited and the values found in our study

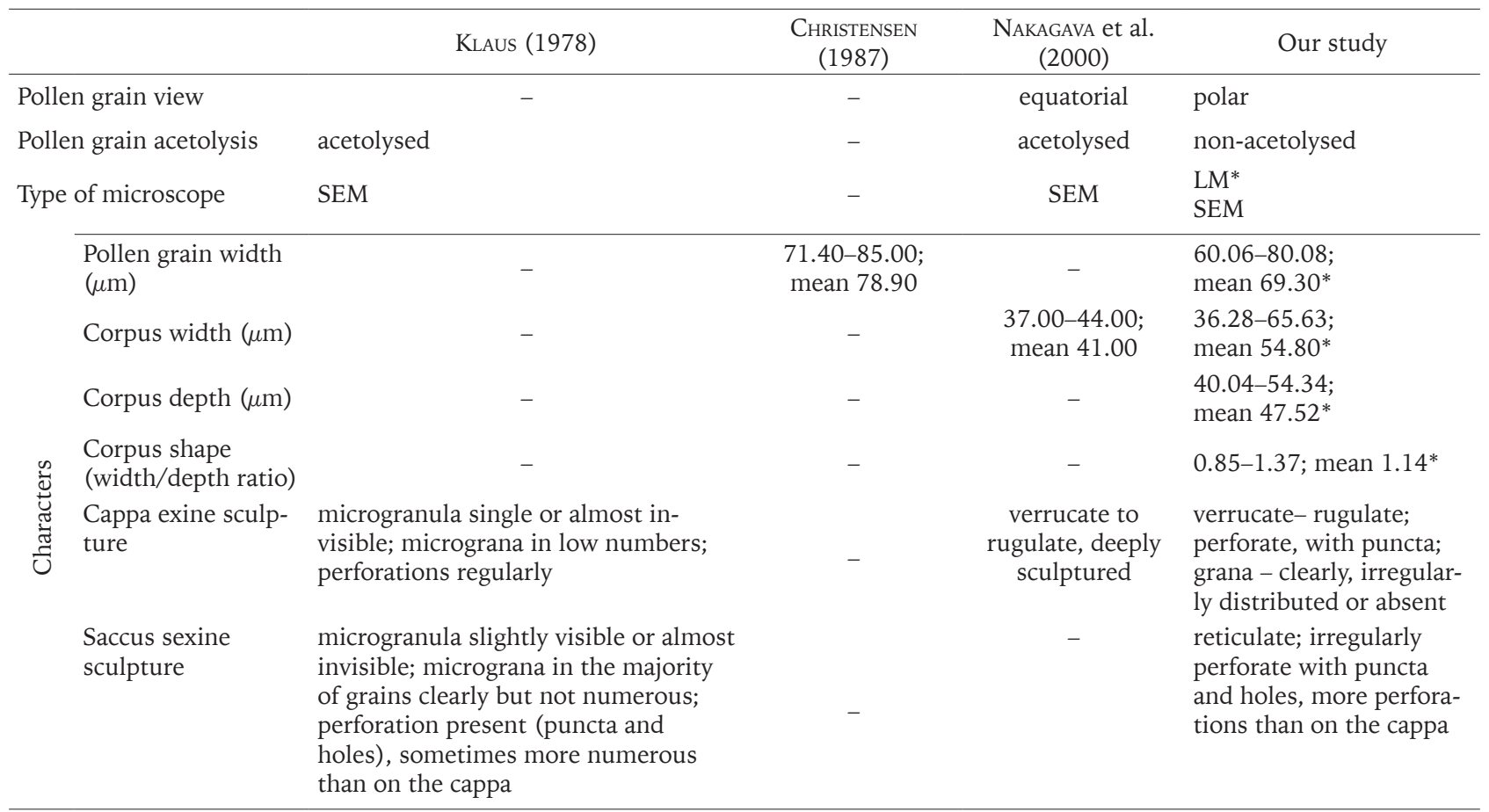


(2015) and P. uncinata (FA) (in terms of the large size of its pollen grains and sacci). The only exception was the distance between the sacci, i.e. $15.63 \mu \mathrm{m}$ in P. uncinata (FA) vs $13.73 \mu \mathrm{m}$ in $P$. $\times$ rhaetica no. 16 FA. Moreover, $P$. uncinata (FA) was distinguished by big sacci (ca. $40 \times 29 \mu \mathrm{m})$. Their size was similar to the size of the sacci in $P . \times$ rhaetica no. 1 FA.

Apart from that, we observed a large width of pollen grain corpuses in both $P$. uncinata specimens under analysis (50.79 and $58.81 \mu \mathrm{m}$ on average). In the study by BYкоwSKa \& KLIMKO (2015) the width of pollen grain corpuses also exceeded $50 \mu \mathrm{m}$ in nine $P$. $\times$ rhaetica specimens.

\section{CONCLUSIONS}

To conclude, our study of the pollen grain morphology of $P$. uliginosa and $P$. uncinata provided some important new data concerning the corpus, saccus, their size and shape, distance between the saccus and the ornamentation on the proximal surface of the corpus and saccus. The biometric measurements of eight quantitative traits were helpful with identification and the differences in the size and shape of the pollen grains and saccus were statistically significant. The shape of the corpus in P. uliginosa was prolate-spheroidal and in $P$. uncinata it was subprolate and prolate-spheroidal.

The tectum surface traits in the proximal view of the corpus and saccus were less variable (except $P$. uncinata FA) and they were not a good criterion for identification of the species under study. Our study shows that several morphological traits of pollen can be of taxonomical value. Thus, this detailed analysis has greatly increased our knowledge of individual species.

\section{ACKNOWLEDGEMENTS}

We would like to thank Ilona Wysakowska for her technical assistance and Wojciech Klimko for his assistance with computer data records. The authors would like to thank two anonymous reviewers for their suggestions and comments made on an earlier version of the manuscript. This study was supported by the Department of Botany and Department of Dendrology and Nursery, Poznań University of Life Sciences.

\section{REFERENCES}

Bagnell JR. C.R. (1975): Species distinction among pollen grains of Abies, Picea, and Pinus in the Rocky Mountain Area (a scanning electron microscope study). Review of Paleobotany and Palynology 19: 203-220.

Boratyńska K., Jasińska A.K., Marcysiak K., SobierajSKA K. (2011): Pinus uliginosa from Czarne Bagno peat-bog (Sudetes) compared morphologically to related Pinus species. Dendrobiology 65: 17-28.

BoratyŃsKa K., LEWANDOWSKA D. (2009): Differences among three populations of Pinus uliginosa and their relation to $P$. sylvestris as expressed by the needle characters. Dendrobiology 61: 37-46.

BusinskÝ R. (1999): Taxonomick studie agregátu Pinus mugo a jeho hybridnich populace. Acta Prùhoniciana 68: 123-144.

Bүкошsкa J., Kцimкo M. (2015): Pollen morphology of Pinus mugo Turra $\times$ Pinus sylvestris L. hybrids and parental species in an experimental culture. Acta Biologica Cracoviensia Series Botanica 57(1): 'accepted article'. DOI: 10.1515/abcsb-2015-0009.

Christensen K.I. (1987): Taxonomic revision of the Pinus mugo complex and $P . \times$ rhaetica (Pinus mugo $\mathrm{x}$ sylvestris L.) (Pinaceae). Nordic Journal of Botany 7, 4: 383-408.

Erdtan G. (1957): Pollen and spore morphology. Plant taxonomy. Gymnospermae, Pteridophyta, Bryophyta. Almquist and Wiksell, Stockholm-New York.

FÆGRI K., IvERSEN J. (1975): Textbook of pollen analysis. 3rd ed. Munksgaard, Copenhagen.

FrederiKsen N.O. (1978): Preservation of cycad and Ginkgo pollen. Review of Paleobotany and Palynology 25: 163-179.

Klaus W. (1978): On the taxonomic significance of tectum sculpture characters in alpine Pinus species. Grana 17: 161-166.

KREMP G.O.W. (1965): Morphologic Encyclopedia of Palynology. The University of Arizona Press, Tucson.

Krzakowa M., Naganowska B., Bobowicz M.A. (1984): Investigations on taxonomic status of Pinus uliginosa Neumann. Bulletin de la Société des Amis des Sciences et des Lettres de Poznań, serié D 24: 87-96.

MARCYSIAK K. (2004): Interpopulational variability of Pinus uncinata Ramond ex DC. in Lam. \& DC. (Pinaceae) cone characters. Dendrobiology 51: 43-51.

Marcysiak K., Boratyńska K., Mazur M. (2003): Variability of Pinus uliginosa cones from the peat-bog in Węgliniec. Dendrobiology 49: 43-47.

Nakagawa T., Edouard J.L., de Beaulieu J.L. (2000): A scanning electron microscopy (SEM) study of sediments from Lake Cristol, southern French Alps, with special reference to the identification of Pinus cembra and other Alpine Pinus species based on SEM pollen morphology. Review of Paleobotany and Palynology 108: 1-15.

Seneta W. (1987): Drzewa i krzewy iglaste. Cz. 2. PWN, Warszawa.

SOBIERAJSKA K., BORATYŃSKA K. (2008): Variability of needle characters of Pinus mugo Turra populations in the Karkonosze Mountains in Poland. Dendrobiology 59: 41-49. 
Staszkiewicz J. (1966): Rozmieszczenie „europejskich" gatunków sosny. Wiadomości Botaniczne 10(2): 105-114.

Staszkiewicz J., Tyszkiewicz M. (1972): Zmienność naturalnych mieszańców Pinus sylvestris L. $\times$ Pinus mugo Turra (= P. ×rotundata Link) w południowo-zachodniej Polsce oraz na wybranych stanowiskach Czech i Moraw. Fragmenta Floristica et Geobotanica 18, 2: 173-191.
SzWEYKOWSKi J. (1969): The variability of Pinus mugo Turra in Poland. Bulletin de la Société des Amis des Sciences et des Lettres de Poznań, serié D 10: 39-54.

For citation: KLIMKo M., ByкоwsKa J. (2015): Pollen morphology of Pinus uliginosa Neum. and Pinus uncinata Ramond ex DC in an experimental culture. Steciana 19(3): 153-161. doi:10.12657/steciana.019.017 